\title{
Promoted Growth of Maize by the Phosphate Solubilizing Bacteria Isolated from North-east China
}

\author{
Hai-Yan Wu ${ }^{1,2}$, Li-Chun Wang', Xing-Ai Gao ${ }^{3}$, Rong-De Jin², Zuo-Wei Fan', \\ Kil-Yong $\mathrm{Kim}^{2,4}$, and Lan-Po Zhao ${ }^{1}$ * \\ ${ }^{1}$ College of Resources and Environment, Jilin Agricultural University, Changchun 130118, China \\ ${ }^{2}$ Agricultural Environment and Resources Research Center, \\ Jilin Academy of agricultural Sciences, Changchun 130033, China \\ ${ }^{3}$ Institute of Rural Energy, Jilin Academy of agricultural Sciences, Changchun 130033, China \\ ${ }^{4}$ Division of Applied Bioscience and Biotechnology, Chonnam National University, Gwangju 500-757, Korea
}

\begin{abstract}
A strain of phosphate solubilizing bacterium was isolated from rhizosphere and identified as Burkholderia sp. by 16S-rRNA gene sequence analyses. The bacterium was found to release gluconic acid and the solubilization of hydroxyapatite in the liquid medium by a significant drop in $\mathrm{pH}$ to $3.7 \mathrm{from}$ an initial $\mathrm{pH}$ 7.0. The soluble-P concentration continuously increased during the incubation periods and the total amount of soluble $P$ released in culture filtrate was detected at $990 \mathrm{mg} \mathrm{L}^{-1}$ after 10 days of inoculation. Most promoted maize growth was found in the standard NPK (240-120-120 kg ha $\left.{ }^{-1}\right)$ soil inoculation with Burkholderia sp. (Twenty milliliters/ plant, $106 \mathrm{CFU}$ ) and also in the absence of Burkholderia sp. inoculation, the soil amended with only 2/3 levels of $P$ gave significant higher plant yield compared to $1 / 3$ levels of $P$ or without $P$ supplementation.
\end{abstract}

Key words: Phosphate solubilizing bacteria, Burkholderia sp., Gluconic acid, Maize

\section{Introduction}

In agriculture, phosphorus $(\mathrm{P})$ is one of the essential mineral fertilizer and represents the world's second largest chemical for plant growth and development. However, available $\mathrm{P}$ in natural soil is easily converted into insoluble complexes such as iron and aluminum hydrous oxides, crystalline and amorphous aluminum silicate, and calcium carbonate. In these forms, $\mathrm{P}$ is highly insoluble and unavailable to plants. Phosphate is thus added to agricultural soil in the form of soluble chemical P fertilizers. However, only a small fraction $(0.1 \%)$ of the added $\mathrm{P}$ is made available to plants (Scheffer and Schachtschabel, 1989) since most of it is rapidly converted into insoluble forms (Reddy et al., 2002) or washed away into fresh and ground waters, making a regular but unfortunately polluting application necessary (Shigaki et al., 2006). The alternative ways include application of efficient microbial inoculants

\footnotetext{
Received : January 12. 2011 Accepted : February 18. 2011

*Corresponding author : Phone: +8643187063813

E-mail: rdkim2008@hanmail.net
}

capable of solubilizing insoluble phosphate in soil environment (Park et al., 2005).

Certain soil microorganisms possess an ability to solubilize insoluble phosphate in soil environment (Goldstein, 1995; Illmer and Schinner, 1992). Many species of bacteria are able to solubilize phosphates in vitro and some of them can mobilize P in plants (Antoun et al., 1998; Chabot et al., 1998). Several reports have examined the ability of different bacterial species to solubilize insoluble inorganic phosphate compounds, such as tricalcium phosphate, dicalcium phosphate, hydroxyapatite, and rock phosphate (Goldstein, 1986). Among the bacterial genera with this capacity are Pseudomonas, Bacillus, Rhizobium, Acetobacter, Agrobacterium, Klebsiella, Enterobacter, Burkholderia, Erwinia species, and acetic bacteria (Hilda and Reyanldo, 1999; Hwangbo et al., 2003).

It is generally accepted that major mechanism of mineral phosphate solubilization is the action of organic acids synthesized by phosphate-solubilizing bacteria (PSB) (Louw and Webley, 1959; Moghimi et al., 1978). Among them, gluconic acid and 2-ketogluconic acid seem to be the most frequent agent insoluble phosphate 
solubilization. Other organic acids, such as oxalic citric, lactic, malonic, butyric, mali, fumaric, and acetic acid, have also been identified among PSB (Kim et al., 1997; Leyval and Bertherin, 1989; Louw and Webley, 1959). This process not only compensates for higher cost of manufacturing fertilizers in industry but also mobilizes the fertilizers added to soil (Rajan et al., 1996). However, several processes of the $\mathrm{P}$ cycle in soils remain obscure, despite large research efforts devoted to increasing the $\mathrm{P}$ availability to plants (Song et al., 2002).

The aims of this study are to isolate phosphate solubilizing bacteria from the maize-cultivated rhizosphere and to investigate the relationships among the phosphate solubilization, the production of organic acids, and $\mathrm{pH}$. Also, this study was to examine the effect of phosphate-solubilizing bacteria as inoculants on plant growth.

\section{Materials and Methods}

Isolation of PSB Rhizosphere soils were taken at a depth of $15-20 \mathrm{~cm}$ from maize cultivated field at Jilin Province, China. Soils were serially diluted in sterile water at a rate of 10-5 and inoculated on hydroxyapatite (HY) agar medium containing glucose, $10 \mathrm{~g}$; $\mathrm{MgSO}_{4}$. $7 \mathrm{H}_{2} \mathrm{O}, 0.4 \mathrm{~g} ; \mathrm{NaCl}, 1 \mathrm{~g} ; \mathrm{CaCl}_{2} \cdot 2 \mathrm{H}_{2} \mathrm{O}, 0.2 \mathrm{~g} ; \mathrm{NH}_{4} \mathrm{NO}_{3}, 1.5$ $\mathrm{g}$; $\mathrm{KCl}, 0.2 \mathrm{~g}$; yeast extract, $0.5 \mathrm{~g}$; hydroxyapatite (HY1 $\mathrm{Ca}_{10}(\mathrm{OH})_{2}(\mathrm{PO} 4)_{6}$; Aldrich Chemical Co.), $4 \mathrm{~g}$; agar, $15 \mathrm{~g}$ per liter of distilled water at $\mathrm{pH} 7.0$ After 3-days inoculation at $28^{\circ} \mathrm{C}$, one bacterium having strong phosphate solubilizing property were selected for further study and further purified by serially plating onto the agar medium supplemented with hydroxyapatite.

Bacterial identification The 16S rRNA gene analyses were performed directly using a single whole colony of the strain isolate, according to the procedure described by Di Cello (1997). The forward primer was 5'-TGGCTCAGAAGCAACGCTGGCGGC- $3^{\prime}$, and the reverse primer was $5^{\prime}$-CCCACTGCTGCCTCCCGTAGGAGT-3'. The temperature cycle was at $94^{\circ} \mathrm{C}$ for 30 seconds, $55^{\circ} \mathrm{C}$ for 1 minute, and $72^{\circ} \mathrm{C}$ for 1 minute 30 seconds for 30 cycles and 5 minutes at $72^{\circ} \mathrm{C}$ for extension. The polymerase chain reaction product was cloned using pGEM-T easy vector (Promega, Madison, WI). The nucleotide sequence of the 16S rRNA gene was determined by Biodye Terminator cycle sequencing kit and compared with published 16S rRNA sequences using Blast search at
Gene Bank Data base of NCBI (Bethesda, MD).

Bacteria growth PSB were grown in $200 \mathrm{~mL}$ liquid $\mathrm{HY}$ medium containing glucose, $10 \mathrm{~g}$; $\mathrm{MgSO}_{4} \cdot 7 \mathrm{H}_{2} \mathrm{O}, 0.4$ $\mathrm{g} ; \mathrm{NaCl}, 1 \mathrm{~g} ; \mathrm{CaCl}_{2} \cdot 2 \mathrm{H}_{2} \mathrm{O}, 0.2 \mathrm{~g} ; \mathrm{NH}_{4} \mathrm{NO}_{3}, 1.5 \mathrm{~g} ; \mathrm{KCl}, 0.2$ $\mathrm{g}$; yeast extract, $0.5 \mathrm{~g}$; hydroxyapatite $\left(\mathrm{HY}_{1} \sim \mathrm{Ca}_{10}(\mathrm{OH})_{2}\right.$ $\left(\mathrm{PO}_{4}\right)_{6}$; Aldrich Chemical Co.), $4 \mathrm{~g}$; agar, $15 \mathrm{~g}$ per liter of distilled water at $\mathrm{pH} 7.0$ on a gyratory shaker (at $200 \mathrm{rpm}$ ) at $30^{\circ} \mathrm{C}$ for 10 day under air supply filtered through a 2 um Whatman membrane filter at $30 \mathrm{~mL} \mathrm{~min}^{-1}$. Uninoculated flasks from each set were treated similarly for control. Flasks were incubated in the dark on a gyratory shaker (200 rpm) at $30^{\circ} \mathrm{C}$ and sampled at $1,2,5,7$, and 10 days for measuring $\mathrm{pH}$, P-solubilization and organic acid concentration. All the experiments were carried out in triplicate.

Determination of $\mathbf{p H}$ and $\mathbf{P}_{2} \mathbf{O}_{5}$ concentration The $\mathrm{pH}$ of broth culture was measured directly by immersing a glass electrode into culture solution. Broth culture was filtered through Whatman No. 6 filter paper as a preliminary step in $\mathrm{P}$ concentration. Fifty $\mu \mathrm{l}$ of filtrate were added into a $20 \mathrm{~mL}$ test tube containing $1.95 \mathrm{~mL}$ extraction solution. To each $2 \mathrm{~mL}$ solution in test tube, $5 \mathrm{~mL}$ of distilled water, $2 \mathrm{~mL}$ of ammonium paramolybdate solution $(12 \mathrm{mM})$, and $1 \mathrm{~mL}$ of $\mathrm{SnCl}_{2}$ solution $(5 \mathrm{mM})$ were added, and then mixed well. After 5-minute incubation, $\mathrm{P}_{2} \mathrm{O}_{5}$ concentrations were measured spectrophotometrically at $660 \mathrm{~nm}$.

Measurement of organic acid For measurement of organic acids, broth culture was filtered through a Whatman $0.2 \mu \mathrm{m}$ membrane filter. Organic acids in filtrate were determined by high performance liquid chromatography (HPLC) (Shimadzu, Japan) with Shodex RSpak KC-811 column $(8 \mathrm{~mm} \times 30 \mathrm{~cm})$. The operating conditions consisted of $0.1 \% \mathrm{H}_{3} \mathrm{PO}_{4}$ as the mobile phase, a constant flow rate of $0.5 \mathrm{~mL} \mathrm{~min}^{-1}$, and sample injection of $20 \mu \mathrm{L}$ under the UV $210 \mathrm{~nm}$. The organic acids were quantitatively determined by comparing peak areas of chromatograms with those of standards.

Plant gnowth The experiment was conducted in field at Jilin province, during May-October 2010. Each treatment was raised in six rows, each of $5 \mathrm{~m}$ length $\times 6 \mathrm{~m}$ width, with an intra- and inter-row spacing 15 and $60 \mathrm{~cm}$. The treatments were arranged in a completely randomized block design with three replications and sown with maize cultivar (JIDAN 260, Jilin Academy of Agriculturl Scien- 
ces) with the plant density 55,000 plants per hectare. At 4 weeks after sowing, twenty milliliters of Burkholderia sp. culture suspension $\left(1 \times 10^{6} \mathrm{CFU} \mathrm{mL}^{-1}\right)$ was amended by pouring into rhizosphere of each maize plant individually and control plants received the same amount of water. The experiment had the following treatments: The five experimental situations tested were the following: (T1) soil with standard N (240 kg ha $\left.{ }^{-1}\right)$ and $\mathrm{K}\left(120 \mathrm{~kg} \mathrm{ha}^{-1}\right)$ supplement with $1 / 3 \mathrm{P}\left(40 \mathrm{~kg} \mathrm{ha}^{-1}\right)$ and inoculated with the culture suspension of Burkholderia sp.; (T2) soil with standard $\mathrm{N}$ and $\mathrm{K}$ supplement with $2 / 3 \mathrm{P}$ and inoculated with the culture suspension of Burkholderia sp.; (T3) soil with standard $\mathrm{N}, \mathrm{K}$, and $\mathrm{P}$ supplementation and inoculated with the culture suspension of Burkholderia sp.; (T4) soil with standard $\mathrm{N}$ and $\mathrm{K}$ supplementation and inoculated with the culture suspension of Burkholderia sp.; (CON) soil with no $\mathrm{N}, \mathrm{K}$ or $\mathrm{P}$ supplementation and without inoculation. Thirty plants were taken from three replications after complete growth period of plants as subsample and growth measurements were recorded.

Statistical analysis The yield was statistically analyzed according to standard procedures including SAS general linear model (GLM), least-significant difference (LSD), and regression procedures (SAS Institute, Cary, $\mathrm{NC})$. Unless otherwise stated, all differences noted in the text were significant at the $5 \%$ level of probability.

\section{Results}

Isolation and identification of PSB One bacterium having strong $\mathrm{P}$ solubilizing ability on HY medium was isolated from the maize field at Gongzhuling area of Jilin Province and then identified as Burkholderia sp. based on their morphology and 16S rRNA analysis (Fig. 1 and 2).
Determination of organic acid production Organic acid produced from the culture filtrate of Burkholderia sp. was carried out at $1,2,5,7$, and 10 days after cultivation by HPLC analysis. The HPLC analysis of culture filtrate revealed that only one major peaks A which was represented as gluconic acid by comparing the retention times with those of the authentic standards (Fig. 3).

Relationships among pH, organic acid production, and P solubilization Burkholderia sp. was incubated on HY broth medium with continuous air supply at $\mathrm{pH} 7.0$ for 10 days. The details of $\mathrm{pH}$ and amounts of soluble-P after $240 \mathrm{~h}$ of incubation are presented in Fig. 4. The solubilization of hydroxyapatite in the liquid medium was derived from a significant drop in $\mathrm{pH}$ to 3.7 from an initial $\mathrm{pH}$ 7.0 after $24 \mathrm{~h}$. The soluble-P concentration continuously increased during the incubation periods and the total amount of soluble $\mathrm{P}$ released in culture filtrate was detected at $990 \mathrm{mg} \mathrm{L}^{-1}$ after 10 days of inoculation.

Growth parameters of maize in field conditions After complete growth period of plants, growth and qualities of

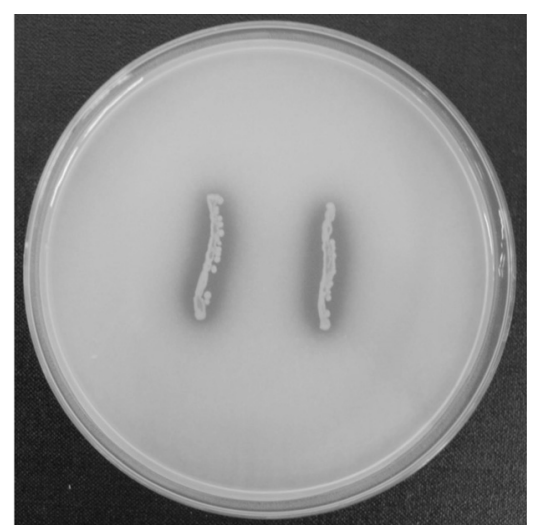

Fig. 1. Clear zones of phosphate solubilization around colonies of Burkholderia sp. on agar medium containing $0.4 \% \mathrm{HY}$ at $28{ }^{\circ} \mathrm{C}$ after 3-days incubation.

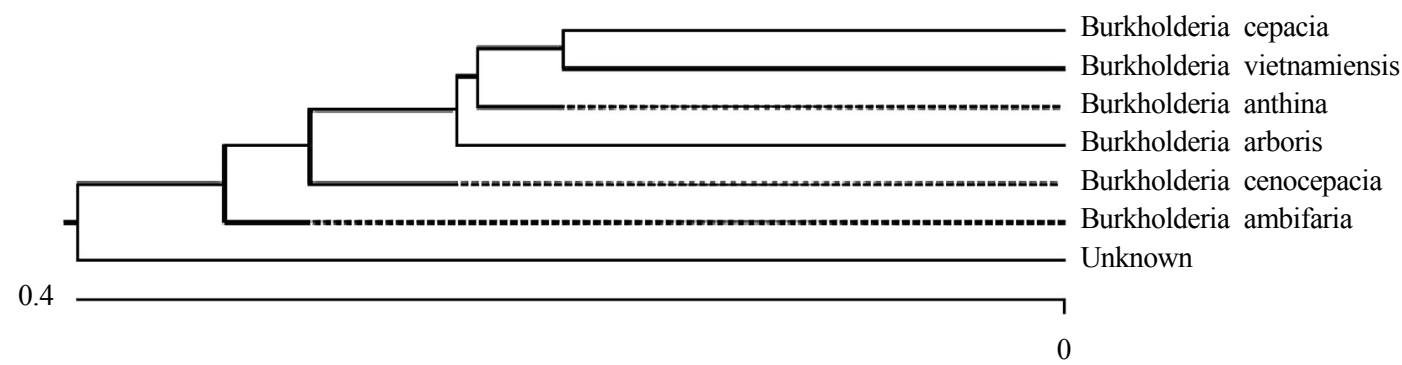

Nucleotide Substitutions $(\times 100)$

Fig. 2. Phylogenic neighbor joining tree obtained with the 16S rRNA gene sequences of members of genus Burkholderia. 


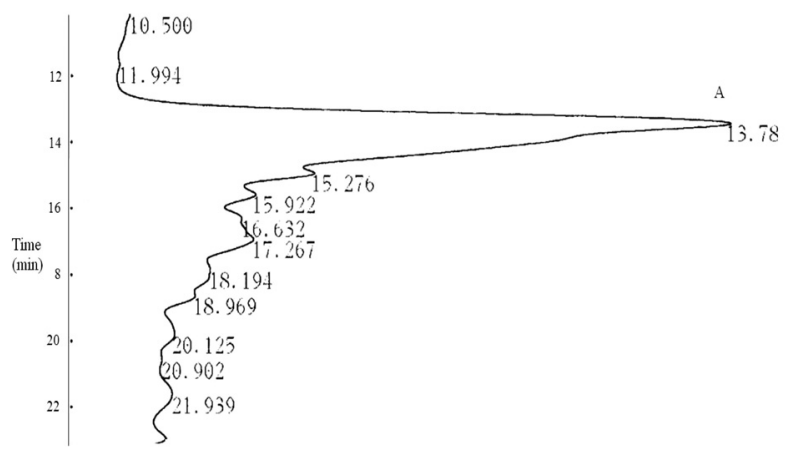

Fig. 3. Typical HPLC chromatograms of gluconic acid produced by Burkholderia sp. on $\mathrm{HY}$ broth at $28^{\circ} \mathrm{C}$ for 3 days.

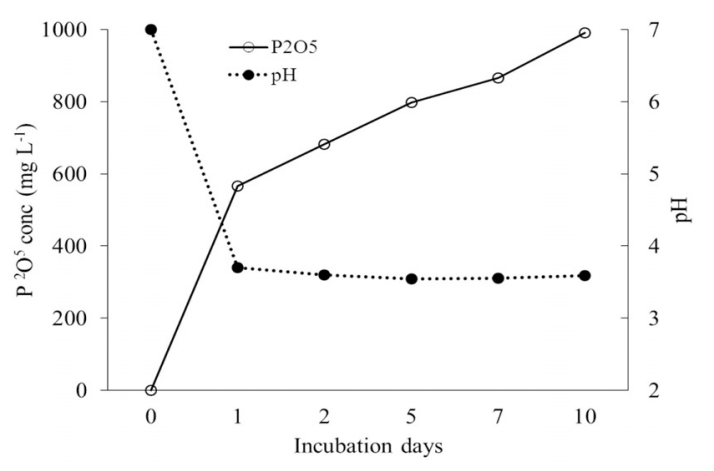

Fig. 4. Changes in $\mathbf{p H}$ and available $P$ concentration by Burkholderia sp. on $\mathrm{HY}$ broth culture at $28^{\circ} \mathrm{C}$ for 10 days.

Table 1. Growth promotion of maize by Burkholderia sp.

\begin{tabular}{ccccccc}
\hline \hline Treatment $^{\dagger}$ & Shoot length & Stem diameter & Leaf area & 100 seed weight & Yield & Kernel rate \\
\hline & $\mathrm{cm}$ & $\mathrm{cm}$ & $\mathrm{m}^{2}$ & $\mathrm{~g}$ & $\mathrm{~kg} \mathrm{ha}^{-1}$ & $\%$ \\
$\mathrm{~T} 1$ & 300 & 2.40 & 0.727 & 39.9 & $9,197 \mathrm{bc}$ & 86.8 \\
$\mathrm{~T} 2$ & 297 & 2.31 & 0.795 & 40.0 & $9,771 \mathrm{ab}$ & 88.6 \\
$\mathrm{~T} 3$ & 295 & 2.39 & 0.793 & 42.0 & $9,941 \mathrm{a}$ & 87.9 \\
$\mathrm{~T} 4$ & 289 & 2.36 & 0.779 & 39.3 & $9,185 \mathrm{bc}$ & 88.0 \\
$\mathrm{CON}$ & 283 & 2.25 & 0.687 & 39.8 & $8,911 \mathrm{c}$ & 87.4 \\
\hline
\end{tabular}

(T1) soil with standard $\mathrm{N}$ and $\mathrm{K}$ supplement with $1 / 3 \mathrm{P}$ and inoculated with the culture suspension of Burkholderia sp.; (T2) soil with standard $\mathrm{N}$ and $\mathrm{K}$ supplement with $2 / 3 \mathrm{P}$ and inoculated with the culture suspension of Burkholderia sp.; (T3) soil with standard N, K, and P supplementation and inoculated with the culture suspension of Burkholderia sp.; (T4) soil with standard $\mathrm{N}$ and $\mathrm{K}$ supplementation and inoculated with the culture suspension of Burkholderia sp.; $(\mathrm{CON})$ soil with no $\mathrm{N}, \mathrm{K}$ or $\mathrm{P}$ supplementation and without inoculation.

maize was measured. Our results (Table 1) demonstrated that, in the absence of Burkholderia sp. inoculation, the soil amended with only $1 / 3$ levels of $\mathrm{P}$ or without $\mathrm{P}$ gave higher plant yield compared to non-NPK supplied CON. Most promoted maize growth was found in the standard NPK (240-120-120 kg ha ${ }^{-1}$ ) soil inoculation with Burkholderia sp. (Twenty milliliters/plant, $10^{6} \mathrm{CFU}$ ) and also in the absence of Burkholderia sp. inoculation, the soil amended with only $2 / 3$ levels of $P$ gave significant higher plant yield compared to $1 / 3$ levels of $\mathrm{P}$ or without $\mathrm{P}$ supplementation. However, no differences were found in the kernel rate among the treatment.

\section{Discussion}

There have been a number of reports on the bacteria that have the ability to solubilize insoluble phosphatic compounds and aid in plant growth (Lifshitz, et al., 1987; Richardson, 1994). Considering that $\mathrm{P}$ availability is a limiting step in plant nutrition (Goldstein, 1986), this evidence suggests a fundamental contribution of phosphate-solubilizing bacteria to plant nutrition and many agricultural microbiologists have been interested in the ability of some bacteria to dissolve insoluble phosphates (Goldstein et al. 1999).

Solubilization of insoluble $\mathrm{P}$ by PSB is mainly derived from the production of organic acids (Illmer et al. 1995; Halder et al. 1991) and our earlier studies (Kim et al. 1997) revealed that phosphate solubilization was due to production of gluconic acid in broth culture medium containing hydroxyapatite. In this study, the soluble P concentration was inversely correlated with $\mathrm{pH}$ in culture medium during the growth period of Burkholderia sp. and it may be derived from the similar mechanism to solubilize insoluble $\mathrm{P}$.

As well as, Chabot et al. (1993) demonstrated growth stimulation of maize and lettuce by several microorganisms capable of mineral phosphate solubilization. A strain of Burkholderia cepacia showing no indole acetic 
acid production, but displaying significant mineral phosphate solubilization and moderate phosphatase activity (Rodríguez, et al., 1996) has improved the yield of tomato, onion, potato, banana, citrics, and coffee, among other cultivars, in field tests, and is currently being used as a commercial biofertilizer in Cuba (Hilda and Reynaldo, 1999). In our study, maize yield was higher in the soil amended with only $1 / 3$ levels of $\mathrm{P}$ or without $\mathrm{P}$ with Burkholderia sp. inoculation promoted plant growth compared to non-NPK supplied CON. We can conclude that phosphate-solubilization effect of Burkholderia sp. seems to be the most important mechanism of plant growth promotion in moderately fertile and very fertile soils.

The selected strain, Burkholderia sp. producing gluconic acid to insoluble inorganic phosphate solubilizing ability seem to have a prospective future in agriculture even this research must be proactive and the field trials must be established across a broad range of soil and environmental conditions and must be conducted within the context of current and/or future farming practices. In some instances, this work is expected to contribute to the development of indoor or outdoor agricultural practices much less polluting than those in current use.

\section{Acknowledgement}

This study was supported by a grant from the main project (Code\#20080254) program, Jilin Provincial Science \& Technology Department, China.

\section{References}

Antoun, H., C.J. Beauchamp, N. Goussard, R. Chabot, and R. Lalande. 1998. Potential of Rhizobium and Bradyrhizobium species as growth promoting rhizobacteria on non-legumes: effect on radishes (Raphanus sativus L.). Pla. Soil 204:57-67.

Chabot, R., H. Antoun, and M.P. Cescas. 1993. Stimulation de la croissance du mais et de la laitue romaine par desmicroorganismes dissolvant le phosphore inorganique. Can. J. Microbiol. 39:941-947.

Chabot, R., C.J. Beauchamp, J.W. Kloepper, and H. Antoun. 1998. Effect of phosphorus on root colonization and growth promotion of maize by bioluminiscent mutants of phosphatesolubilizing Rhizobium leguminosarum biovar phaseoli. Soi. Biolo. Biochem. 30:1615-1618.

Di Cello, F., A. Bevivino, L.Chiarini, R. Fani, D. Paffetti, S. Tabacchioni, and C. Dalmastri. 1997. Biodiversity of a Burkholderia cepacia population isolated from the maize rhizoshere at different plant growth stages. Appl. Environ. Microb. 63: 4485-4493.

Goldstein, A.H. 1986. Bacterial mineral phosphate solubilization: Historical perspective and future prospects. Am. J. Altern. Agric. 1:57-65.

Goldstein, A.H. 1995. Recent progress in understanding the molecular-genetics and biochemistry of calcium-phosphate solubilization by gram-negative bacteria. Biol. Agric. Hortic. 12:185-193.

Goldstein, A.H., K. Braverman, and N. Osorio. 1999. Evidence for mutualism between a plant growing in a phosphate-limited desert environment and a mineral phosphate solubilizing (MPS) bacterium. FEMS Microbiol. Ecol. 3:295.300.

Halder A.K., A.K. Misra, and P.K. Chakrabarty. 1991. Solubilization of inorganic phosphates by Bradyrhizobium. Indian J. Exp. Biol. 29:28-31

Hilda, R. and F. Reyanldo. 1999. Phosphate solubilizing bacteria and their role in plant growth promotion. Biotechnol Adv. 17: 319-339.

Hwangbo, H., R.D. Park, Y.W. Kim, Y.S. Rim, K.H. Park, T.H. Kim, J. S. Suh, and K.Y. Kim. 2003. 2-ketogluconic acid production and phosphate solubilization by Enterobacter intermedium. Curr. Microbiol. 47:87-92.

Illmer, P. and F. Schinner. 1992. Solubilization of inorganic phosphates by microorganisms isolated from forest soils. Soi Biologi Biochemistry 24:389-395.

Illmer, P., A. Barbato, and F. Schinner. 1995. Solubilization of hardly-soluble AlPO4 with P-solubilizing microorganisms. Soil Biol. Biochem. 27:265-270.

Kim K.Y., G.A. McDonald, and D. Jordan. 1997. Solubilization of hydroxyapatite by Enterobacter agglomerans and cloned Escherichia coli in culture medium. Biol. Fert. Soils. 24:347352

Leyval, C. and J. Bertherin. 1989. Interactions between Laccaria laccata, Agrobacterium radiobacter and beech roots: Influence on $\mathrm{P}, \mathrm{K}, \mathrm{Mg}$ and $\mathrm{Fe}$ mobilization from minerals and plant growth. Pla. Soil 117:103-110.

Lifshitz, R., J.W. Kloepper, M. Kozlowski, C. Simonson, J. Carlson, E.M. Tipping, and I. Zalesca. 1987. Growth promotion of canola (rapeseed) seedlings by a strain of Psedomonas putida under gnotobiotic conditions. Can. J. Microbiol. 33: 390-395.

Louw, H.A. and D.M. Webley. 1959. The bacteriology of the root region of the oat plant grown under controlled pot culture conditions. J. Appl. Microbiol. 22:216-226.

Moghimi, A., M.E. Tate, and I.M. Oades. 1978. Characterization of rhizosphere products. especially 2-ketogluconic acid. Soil. Biol. Biochem. 10:77-281.

Park, B.K., H. Hwangbo, I.J. Lee, K.Y. Kim, and K.Y. Kim. 2005. Effect of phosphate bio-fertilizer produced by Enterobacter intermedium on rhizosphere soil properties and lettuce growth. Korean J. Soil Sci. Fert. 38:15-24.

Rajan, S.S.S., J.H. Watkinson, and A. G. Sinclair. 1996. Phosphate rocks for direct application to soil. Adv. Agron. 57:77-159.

Reddy, M.S., S. Kumar, K. Babita, and M.S. Reddy. 2002. Biosolubilization of poorly soluble rock phosphates by 
Aspergillus tubingensis and Aspergillus niger. Bioresource Technol. 84:187-189.

Richardson, A.E. 1994. Soil microorganisms and phosphorus availability. In: Pankhurst CE,

Doube B.M., V.V.S.R. Grupta, and P.R. Grace, editors. Soil Biota, Management in Sustainable Farming Systems. Melbourne, Australia: CSIRO, 50-62.

Rodríguez, H., I. Goire, and M. Rodríguez. 1996. Caracterización de cepas de Pseudomonas solubilizadoras de fósforo. Rev
ICIDCA 30, 47-54.

Scheffer, F. and P. Schachtschabel. 1989. Lehrbuch der Bodenkunde. In: Enke Verlag (Eds.), Stuttgart, Germany, pp. 491

Shigaki, F., A.N. Sharpley, and L.I. Prochnow. 2006. Animalbased agriculture, phosphorus and management and water quality in Brazil: options for the future. Sci. Agr. 63:194-209.

Song, Y.C., X.L. Li, and P. Christie. 2002. Uptake of organic phosphorus by arbuscular mycorrhizal red clover. Pedosphere 12:103-110 